\title{
Anar al cine amb Donna Haraway. En busca d'un cinema situat.
}

\section{Pau Pericas}

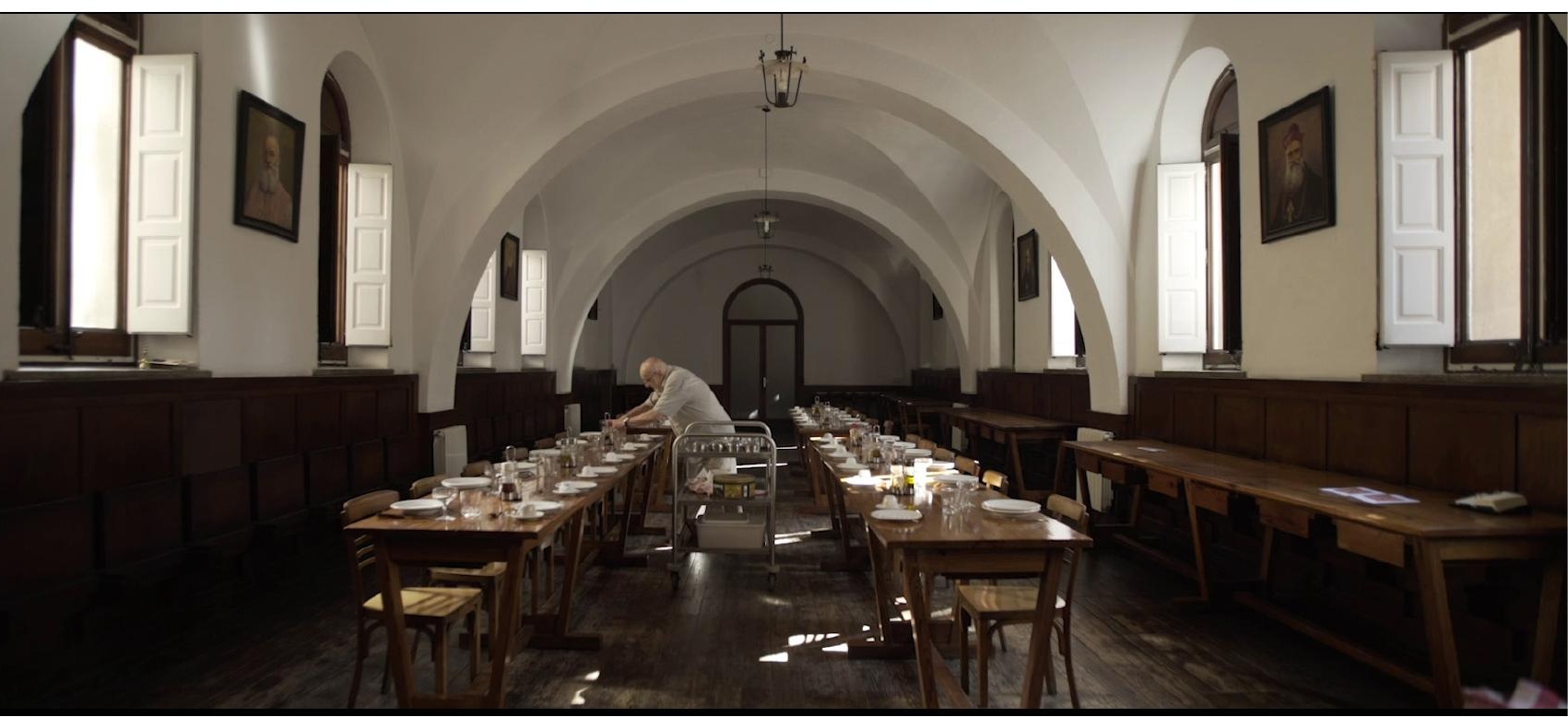

Rebut: 10.05.2021

Revisat: 11.06 .2021

Publicat: 30.06 .2021

Com citar aquest article

Pericas,P., 2021. Anar al cine amb Donna Haraway. En busca d'un cinema situat. Inmaterial. Diseño, Arte y Sociedad, 6 (11), pp. 92-111

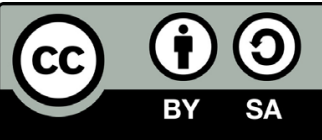




\section{Resum}

En primer lloc, i a través de les nocions d’objectivitat feminista i coneixements situats que proposa Donna Haraway al seu assaig Simians, Cyborgs and Women: The Reinvention of Nature (1991), aquest article intenta esbrinar com es pot produir un cinema situat. La intenció de fons és investigar quan -i en quines condicions- la creació fílmica pot convertir-se en coneixement útil i transferible. L'article incorpora un teaser audiovisual del film, emmarcat dins la tesi doctoral basada en una pràctica que porto a terme a la Unitat de Doctorat i Recerca de BAU (UVic-UCC), i proposa la idea de cinema situat com a forma d'anàlisi fílmica. L'objectiu d'aquesta guia és analitzar, tenint en compte sobretot les problemàtiques i contradiccions, el grau de situació de la mateixa creació fílmica, i alhora intentar minimitzar-les.

Paraules clau: teoria del cinema, epistemologia, investigació basada en pràctica, objectivitat feminista, coneixements situats.

\section{Abstract}

First, and through the notions of feminist objectivity and situated knowledge proposed by Donna Haraway in her essay "Simians, Cyborgs and Women: The Reinvention of Nature" (1991), this article aims to find out how situated cinema can be produced. The underlying intention is to investigate when - and under which conditions-filmic creation can become useful and transferable knowledge. The article incorporates an audiovisual teaser of the film (framed within the practice part of a PhD programme) that I am currently producing at the Doctoral and Research Unit in BAU (UVic-UCC) and proposes the idea of situated cinema as a form of filmic analysis. With this guide, the aim is to analyze - pinpointing above all the problems and contradictionsthe degree of situation in filmic creation itself, while seeking ways how to minimize them.

Keywords: film theory, epistemology, practice-based research, feminist objectivity, situated knowledges. 
L'any 1991, la biòloga i filòsofa estatunidenca Donna Haraway va publicar Simians, Cyborgs and Women: The Reinvention of Nature. Lassaig -especulatiu, visionari, impur i solidari- em va travessar. És una resposta encoratjadora i útil -amb perspectiva i alguna certesa- davant aquell relativisme tan incòmode de la postmodernitat. L'autora proposa una objectivitat feminista basada en els coneixements situats. No existeix l'objectivitat, "la racionalitat és senzillament impossible" (Haraway, 1995, p. 333). De fet, cada vegada que parlem, podem explicitar qui parla i des d'on parla. Fer-se càrrec que parlem des d'un cos, amb unes característiques específiques -gènere, ètnia, nació, classe i molt més-és el primer pas cap a una objectivitat feminista. Els coneixements situats són aquells coneixements que se saben i es manifesten encarnats, parcials, amb una localització limitada i crítics (Haraway, 1995, p. 329), i que es desempalleguen de la veritat en favor d'una perspectiva manifesta, particular i específica, i d'un espai de negociació obert i solidari. La finalitat és que hi hagi millors versions del món. (Haraway, 1995, p. 338).

Des de la seva formació i la seva pràctica dins l'àmbit de les ciències naturals, com a biòloga i zoòloga, l'escriptora denuncia que darrere de la ciència (encara) hi ha el patriarcat ${ }^{1}$. En aquesta mirada situada que proposa, l'objectivitat feminista demana fer explícites les relacions que operen entre les implicades i trencar amb les estructures de poder. Haraway proposa una forma de fer epistemologia, de fer ciència, però també de fer política. El coneixement situat ens convida en última instància a mirar, ser i actuar de forma situada -encarnada, parcial, negociadora i solidària-, i ens apel.la a totes en la nostra relació amb les altres, amb l'entorn i amb nosaltres mateixes. És tot allò que fem -i no fem- allò que podem fer de forma situada.

La pregunta principal plantejada a la meva recerca doctoral és: Quan, com i en quines condicions- pot ser la creació fílmica també una recerca acadèmica? Quan pensa el cinema i pot convertir-se en coneixement útil i transferible? Sembla clar que, si Haraway ens proposa una forma de produir coneixement vàlid, i una forma útil i solidària d'entendre l'epistemologia, serà valuós estudiar com podem produir un cinema si-

\footnotetext{
${ }^{1}$ La denúncia apareix al primer apartat del capítol 7 de l’assaig (Haraway, 1995, p. 313-323). Com argumenta Boaventura de Sousa Santos, el patriarcat, el colonialisme i el capitalisme actuen junts (2017). Sobre el tema, també Garcés (2017), Herrero (2018) i Taibo (2017). Em sumo a la proposta a favor d'una objectivitat feminista, decolonial i anticapitalista.
} 
tuat. Rellegir l'assaig de Haraway desplaçant el concepte de coneixement situat a cinema situat ofereix una reflexió profunda sobre una forma ${ }^{2}$ de creació audiovisual que, parcial i localitzada, pot ser generadora d'un saber vàlid. Amb la mirada posada en la creació fílmica, l’anàlisi detallada de les idees de Haraway permet establir paral.lelismes amb algunes concepcions històriques del cinema, amb les idees d'alguns teòrics $\mathrm{i}$ amb la filmografia de diverses cineastes, des del cinema dels orígens fins a l'audiovisual contemporani entès en el seu sentit més ampli.

Un cinema situat és el que -sobretot i abans que res- es produeix de manera parcial i localitzada, el que evita el que és incorpori i universalitzant. "L'única manera de trobar una visió més àmplia és estar en algun lloc en particular" (Haraway, 1995, p. 339). És aquella forma fílmica que no pretén oferir la realitat sinó proposar-ne una perspectiva encarnada i negociable. És un cinema que denuncia els abusos de poder i usa formes d'expressió que no recorren a res determinat per fer-ho. Aquesta forma posicionada de generar coneixement útil que proposa Haraway és alhora política i ideològica. Quan trasllado aquestes primeres idees a la història del cinema, ràpidament em venen al cap els constructivistes soviètics. La ideologia que fonamenta el cinema dialèctic d'Eisenstein exclou tota consideració d'una suposada realitat que tingui en si mateixa un sentit propi. Per al constructivista, "la realitat no té cap interès fora del sentit que li atorguem, de la lectura que en fem.” Des d’aquesta mirada, “el cinema no té pas l'obligació de reproduir la realitat sense intervenir-hi sinó, ben al contrari, reflectir aquesta realitat i oferir-ne al mateix temps un cert judici ideològic" (Aumont, Bergala, Marie i Vernet, 1983, p. 81). Per als soviètics de principis del segle XX, el film és un text per repassar la història i expressar opinions, i el muntatge és la clau de la seva sintaxi. La seva manera de juxtaposar imatges suposa un trencament total de la continuïtat i posa de manifest contrastos crítics, estableix comparacions, crea metàfores, proposa relacions de causalitat i genera símbols. D’alguna manera, el text fílmic dels constructivistes s'assimila a un text epistemològic situat: vol proposar pensament des d'alguna certesa compartida i amb un punt de vista manifest, innovador i crític, sobretot amb qui ostenta el poder.

\footnotetext{
2 "En una pel-lícula tot és forma", recorda la veu de Johan Van Der Keuken al seu film Herman Slobbe (Blind Child 2), de l'any 1966, que representa dos camperols espanyols que treballen la terra. Menys categòric, Bill Nichols ens recorda que els significants cinematogràfics són imatges i sons, i són sempre concrets, materials i específics. El que els films han de dir no es pot separar de com ho diuen. (Nichols, 1997, p. 18). Al film Où git votre sourire enfoui? (Pedro Costa, 2001), Jean-Marie Straub assegura que la forma emergeix a través de la lluita entre la idea i la matèria (fílmica).
} 
Els ulls, assegura Haraway, han estat usats per expressar una perversa capacitat -relacionada amb el militarisme, el capitalisme, el colonialisme i el masclisme- que desencarna el subjecte coneixedor de l'interès del poder. "La vista en aquesta festa tecnològica s'ha convertit en golosia incontenible" (Haraway, 1995, p. 325). La idea connecta directament amb la societat de l'espectacle descrita per Guy Debord a La Société du Spectacle (1967). Ara que les relacions socials entre persones estan més mediatitzades per les imatges que mai i ara que tenim un espectre polític internacional dominat per la noció de l'espectacle, quin cinema té sentit produir per atorgar als ulls poder crític i proposar una doctrina de l'objectivitat usable, tot i no ser innocent? "Com es pot aprendre a veure amb l'altre sense pretendre ser l'altre?” (Haraway, 1995, p. 332). Aquesta forma fílmica situada, posicionada, no cedeix davant "els mites temptadors de la visió" i proposa un coneixement amb i des del cos, en "color primat” i "visió estereoscòpica” (Haraway, 1995, p. 326).

El cinema situat assumeix la subjectivitat de qualsevol proposta cinematogràfica, sigui del model audiovisual que sigui. "Tot film és un film de ficció”3 (Aumont, Bergala, Marie i Vernet, 1983, p. 100). La suposada neutralitat i igualtat de posicionament és una negació de la responsabilitat i de la recerca crítica. El cinema que estic buscant ha superat aquella idea cartesiana que considera el documental com a un tipus de film objectiu que parla sobre la realitat sense posicionar-se. És precisament amb el reconeixement conscient i manifest de la nostra subjectivitat específica que podem acostar-nos a una nova forma d'objectivitat feminista (postcolonial i crítica amb el capitalisme). Aquest cinema ha abandonat la lògica del descobriment per treballar des d'una "relació social de conversa carregada de poder" "El món no parla ni desapareix a favor d'un amo descodificador" (Haraway, 1995, p. 342). D'altra banda, res és determinat ni fixe i els objectes de coneixement no són passius ni inerts. (Haraway, 1995, p. 340-343). El cinema situat, doncs, no pretén comunicar el que ha descobert de la realitat, sinó que més aviat pretén

\footnotetext{
${ }^{3}$ Donada la seva matèria d'expressió (imatges en moviment i so), tot film torna irrealitzable el que representa i ho converteix en espectacle. Una peça audiovisual presenta sempre un caràcter fantàstic d'una realitat que no pot copsar del tot. El dispositiu tècnic de filmació i projecció, i la preocupació estètica, també present al cinema del que és real, transformen el missatge en un objecte de contemplació, en una visió, que s’acosta al que és imaginari. Tot objecte és signe d'una altra cosa, està pres d'un imaginari social i s'ofereix com a suport d'una petita ficció. (Aumont, Bergala, Marie i Vernet, 1983, p. 100-102). El pensador Jaques Derrida encara va molt més enllà quan assegura que el cinema ens endinsa a l'univers de l'espectre, "potencia el regne dels fantasmes i la seva capacitat per perseguir-nos". El filòsof en parla al film Ghost Dance (Ken McMullen, 1983).
} 
generar diàleg i reflexió compartida des d'una visió oberta -interpretativa, crítica, mutable i parcial- de la realitat ${ }^{4}$.

Una forma cinematogràfica situada pren també consciència de les implicacions dels mitjans de captació i reproducció d'imatges i sons. Filmar un primer pla amb un teleobjectiu des de la distància o fer-ho amb una lent angular de ben a prop comporta distintes implicacions visuals i emotives, i suposa diferents relacions -físiques, com a mínimentre la realitzadora i el personatge. "La visió requereix instruments visuals; una òptica és una política del posicionament." (Haraway, 1995, p. 332). El metacomentari, el que és metacinematogràfic i autoconscient, apareix sovint en la forma fílmica situada. Aquest fet s'aconsegueix precisament perquè es fa explícit el dispositiu mediador entre realitat $\mathrm{i}$ audiència. Aquesta encarnació particular i específica del cinema situat no demana només assumir que "el jo que coneix és parcial en totes les seves facetes" (Haraway, 1995, p. 331), sinó també fer-se càrrec de les conseqüències del seu sistema de representació. El film situat es fa autoconscient per posar de manifest la illlusió, ficció o dramatització, també en l'aspecte més tècnic, matèric i específic de la seva expressió ${ }^{5}$. Per tal d’oferir una anàlisi més profunda a través d'un cas concret, m’agradaria recuperar aquí el film Los espigadores y la espigadora (Agnès Varda, 2000). Al film, Varda recorre França en la cerca de persones recol.lectores que, per necessitat o ideologia, busquen objectes o aliments rebutjats per altres persones. La mateixa cineasta es considera també recol.lectora en la mesura que busca i colllecciona testimonis per al seu film. Per al meu estudi, resulta significativa l'escena en la qual la directora es presenta amb la seva nova càmera i comenta: "Aquestes càmeres noves, digitals i fantàstiques permeten aconseguir efectes es-

\footnotetext{
${ }^{4}$ El cinema feminista ha sigut i segueix sent fonamental per a aquest discurs. Incorporar la mirada feminista dins la representació audiovisual ha contribuït enormement a denunciar el poder cisheteropatriarcal $i$ ha permès fer visible un vast conjunt de motius i formes de fer-cabdals per a un cinema situat- que havien estat obviats fins ara. Els feminismes han canviat la manera de percebre el món i han transformat el llenguatge audiovisual. Gràcies a la seva mirada, s' ha començat a representar - de forma honesta, encarnada, crítica, inclusiva i solidària- la intimitat i la quotidianitat, la sexualitat, la família, els drets reproductius, la maternitat, les cures, la violència domèstica... Aquest fet ha estat imprescindible per posar de manifest moltes desigualtats de facto i injustícies legals. Vull destacar l'obra de cineastes com ara Alice Guy, Maya Deren, Yvonne Rainer, Carole Roussopoulos, Barbara Hammer, Ulrike Ottinger, Cecília Bartolomé, Chantal Akerman, Claire Simon, Agnès Varda, Trinh T. Minh-ha, Naomi Kawase, Maria Ruido, Carolina Astudillo i Xiana do Teixeiro.
}

${ }^{5}$ Del cinema modern al contemporani, són moltes les cineastes que considero que han realitzat films autoconscients i situats de gran valor epistemològic. A banda de les dones cineastes ja esmentades, cal destacar David Perlov, Jonas Mekas, Stan Brakhage, Chris Marker, Johan Ven Der Keuken, Pier Paolo Pasolini, Jean Rouch, Jean-Luc Godard, Gustav Deutsch, Raúl Ruiz, Jean-Pierre Gorin, Michal Aviad, Lisl Ponger, Harun Farocki, Hito Steyerl, Gaëlle Vu, Yue-Qing Yang, Carla Subirana, Miguel Gomes, León Siminiani i Andrés Duque. La llista és incompleta, parcial i subjectiva. 
troboscòpics, narcísics i, fins i tot, hiperrealistes." Mentre la sentim, ens ofereix imatges d'ella mateixa gravades amb alguns efectes de la càmera: glitch, obturacions lentes i sobreexposicions. Fins i tot ens mostra el manual d'instruccions de la càmera. En una altra escena, Varda s'oblida d'apagar la càmera i les imatges mostren el terra mentre la realitzadora es desplaça. Al camp visual apareix també la tapa de l'objectiu de la càmera que es mou al ritme dels passos. La veu de Varda bateja l'escena amb el següent títol: "La dansa de la tapa de l’objectiu”. En ambdues escenes, la mostra del dispositiu de filmació no pot ser més explícita. Per últim, m’interessa també com Varda decideix allargar alguns plans més del que seria habitual en una producció canònica, deixant les cues de les preses muntades, on apareixen comentaris off the record dels testimonis. Recordo el cas del primer personatge del film, l'agricultora que rememora l'època en la qual s'espigava a mà. En acabar el seu testimoni a càmera, marxa de pla mentre sentim que diu a algú fora de camp: "M'han enxampat desprevinguda." Aquest muntatge mostra les costures de la pel.lícula, contribueix a fer el film autoconscient i atorga espontaneïtat, parcialitat i naturalitat als personatges i al text fílmic. A més, suposa una resistència contra una estètica imperant.

Un cinema situat és també el que té preferència per adoptar el punt de vista del subjugat, no pas perquè es considera innocent sinó, ben al contrari, perquè es creu que proposa "versions transformadores més adequades, sustentades i objectives del món" (Haraway, 1995, p. 328). És un cinema "contra la visió des de dalt, des d'enlloc, des de la neciesa." (Haraway, 1995, p. 335). L'autora explicita que les posicions dels subjugats no estan exemptes d'avaluació crítica, desconstrucció ni interpretació. Pensant en la representació audiovisual, convé recordar aquí la idea de la política de la identitat: Qui i en quines condicions es pot erigir per representar a quin col-lectiu oprimit o grup social vulnerat? Com pot la realitzadora treballar d'una manera no jeràrquica amb les dones que no tenen cap poder? Com es pot assegurar que la producció i distribució del film serà pel bé de la comunitat representada ${ }^{6}$ ?

\footnotetext{
${ }^{6}$ Les obres fílmiques de les cineastes feministes esmentades conformen una mostra de la bona praxis en la representació de grups socials oprimits i/o vulnerables. Han representat sobretot a les dones, però també sovint a les lesbianes, els gais, els bisexuals, els transsexuals i també altres col.lectius -grups ètnics i dissidents polítics, entre d'altres- que no estan formats per dones. Cal destacar el film Reassemblage: From the Firelight to the Screen (Trinh T. Minha-ha, 1982), que suposa un original estudi cinematogràfic de les dones del Senegal rural i va ser una gran influència per a l'etnografia experimental de principis dels anys vuitanta. Al panorama nacional contemporani, destacaria el film El año del descubrimiento (Luis López Carrasco, 2020), projectat internacionalment i guanyador de dos premis Goya en aquesta darrera edició, millor documental i millor muntatge.
} 
Una forma de cinema situat no porta les actrius del film -tant si es representen a si mateixes com si representen personatges de ficció- a una posada en escena que no controlen o viuen amb disgust, ni les fa participar en un film que no comprenen. Al contrari, és un cinema inclusiu i participatiu, que vol ser útil per a les dones a les quals representa ${ }^{7}$ Em sembla d'interès comentar aquí la implicació de la cineasta Barbara Hammer en la visibilitat del col-lectiu LGTBIQ. Tal com explica la historiadora, professora i codirectora de la Mostra Internacional de Films de Dones de Barcelona, Marta Selva (2020), la importància de l'obra de Hammer no es basa només en el posicionament polític de l'artista, sinó també en la seva perspectiva comunitària, en el seu treball relacional i en la innovació en les formes de representació. En declarar-se lesbiana públicament, la cineasta va passar a formar part del col-lectiu al qual representava. D'una manera o altra, Hammer s'exposa a pràcticament les més de vuitanta produccions que ha realitzat. Lluny de ser una forma d'egocentrisme, per a la realitzadora això suposa una manera de comprometre's, amb i des del cos, amb el col-lectiu LGTBIQ, que als inicis del seu camí cinematogràfic encara no estava representat.

Bill Nichols reflexiona sobre el problema que suposa la tradició documental que converteix els personatges -ell en diu "actors socials"- en víctimes. "La victimització és una mutilació o assassinat de l'individu per produir una tipificació o estereotip” (Nichols, 1997, p. 132). El cinema situat no simplifica el subjecte que representa, buscant l'encaix en l'estructura del conte mític, ni el degrada fent-li fer el paper que necessita el film en funció del tractament dramàtic de la realitat. "L'objectivitat feminista resisteix la simplificació en última instància” (Haraway, 1995, p. 337-338). La política de l'espai, l’estipulació dels límits i el manteniment dels recursos de distanciament són les fórmules que l'autor estatunidenc concreta per evitar la victimització. Podem trobar una excel.lent mostra d'aquests mecanismes al film El fuego inextinguible (Harun Farocki, 1969). La pel.lícula denuncia l'ús del napalm a la Guerra del Vietnam i comença narrant l'atac d'una bomba de napalm sobre Thai Bihn Dahm, un jove de nacionalitat vietnamita. Durant el relat, lluny de mostrar imatges del país asiàtic en flames o d'éssers humans desfigurats, les imat-

\footnotetext{
${ }^{7}$ Per tot el territori català, i a través d'entitats com ara la Cooperativa d’Audiovisuals Drac Màgic i A Bao A Qu, s'estan portant a terme projectes de cinema participatiu de gran valor social, polític i cultural. Pels meus anys d'experiència colllaborant amb el Drac Màgic, opino que el cinema creat en collectiu, en projectes participatius i amb finalitats socials no lucratives, és una de les pràctiques més potents d'entre totes les pràctiques fílmiques situades.
} 
ges mostren al mateix Farocki, vestit amb americana i corbata, en un interior neutre i assegut davant una taula, llegint el text de Bihn Dahm. El relat oral és terrible -l'afectat va patir cremades al rostre, als braços i a les cames, i va quedar tretze dies inconscient- però les imatges mostrades es distancien completament de l'horror, sortejant la victimització i escapant de la imatge-espectacle. En acabar el relat del vietnamita, el realitzador alemany mira a càmera i fa una pregunta clara i directa a l'audiència: "Com podem mostrar el napalm en acció?" Seguidament, reflexiona en veu alta i descarta mostrar imatges de pells socarrimades i d'éssers humans estrafets. Per tancar l'escena, ell mateix s'apaga una cigarreta al braç i, a través d'una veu over, se’ns informa: "Una cigarreta crema a 400 ॰C. El napalm crema aproximadament a 3.000 `C." A continuació, la veu dona dades esfereïdores sobre la crema de napalm: allibera gasos tòxics que afecten la respiració, la supervivència és pràcticament impossible a un radi de vuitanta metres, quan crema no es pot retirar de la pell i crema també la carn i, fins i tot, els ossos. L'única imatge que acompanya la veu és un sac de napalm en flames.

El cinema que estic buscant "afavoreix la contestació, la desconstrucció, la construcció apassionada i les connexions entrellaçades, i mira de transformar els sistemes de coneixement i les maneres de mirar" (Haraway, 1995, p. 329). En primer lloc, busco un cinema que desconstrueix, que separa les parts per mirar el tot d'una manera nova i que afavoreix l'anàlisi crítica. A més, estic parlant d'un cinema contestatari, que qüestiona el sistema politicosocial establert i lluita contra la lògica produccionista de les tradicions binàries occidentals. El cinema situat és evidentment un cinema polític: tota representació -o omissió- és en última instància un acte polític. El cinema situat es preocupa de la política i també de l'ètica de les imatges ${ }^{8}$. "Ocupar un lloc implica responsabilitat a les nostres pràctiques” (Haraway, 1995, p. 333). El film Margarita y el lobo (Cecília Bartolomé, 1969) és una tragicomèdia musical que posa de manifest la subjugació de la dona a l'Espanya franquista i proposa una crítica mordaç, a través de la sàtira, de la societat industrial i de consum. Per fer-ho, la cinta usa molts mecanismes diversos que van més enllà del cànon comercial, propis de la nouvelle vague

\footnotetext{
${ }^{8}$ No només el considerat cinema documental (o cinema del real) i assagístic pot ser situat. Part del cinema híbrid que usa mecanismes propis de la ficció i/o del cinema experimental per parlar del món històric, però també alguns films de ficció, formen part del corpus situat, en la mesura que proposen una mirada local, posicionada, ideològica i dialogant. Són d'interès sobretot aquells films les creadores dels quals es preocupen de l’impacte social i polític abans, durant i després de ser produïts.
} 
i el situacionisme. Destacaria el constant trencament de la continuïtat a través de l'alternança entre un muntatge narratiu i continuista i un muntatge fragmentari, inharmoniós i discordant, basat en la repetició de plans, la congelació de fotogrames, la juxtaposició rítmica de plans de molt curta durada i la ruptura de la sincronia entre imatge i so. Pel que fa a la responsabilitat de la cineasta, convé recordar aquí que el film va ser censurat fins a la caiguda del dictador i la directora va passar a les llistes negres del Ministeri de Cultura espanyol durant un llarg període. Bartolomé va dirigir el seu primer llargmetratge-Margarita y el lobo és un migmetratge- gairebé una dècada després.

En segon lloc, es proposa un cinema que pretén generar un conjunt de sabers utilitzables sense renunciar a la passió. Des dels seus orígens, l'emoció és una de les dimensions fonamentals del fenomen cinematogràfic. En la meva experiència ${ }^{9}$, l'emoció -l'humor, el drama i el suspens- conté un enorme potencial en l’àmbit de l'educació i l'aprenentatge. Com podem usar l'emoció eficaçment en la transferència de coneixements? Al film Apuntes para una película de atracos (León Siminiani, 2018), el director proposa un treball autobiogràfic que és alhora una recerca documental sobre un atracador de bancs madrileny conegut com a "Robin Hood de Vallecas". El realitzador comparteix tot el seu procés de manera honesta, clara i directa, des del primer contacte amb el lladre, detingut a la presó, fins a la relació personal que estableixen al final del film. El director comparteix les pors, les angoixes i les alegries del contacte amb l'atracador i la realització del film, però també les de caire personal: la relació amb la seva parella, el seu primer embaràs i el naixement del seu fill. Així doncs, d'una manera molt particular i situada, Siminiani s'acosta a la dimensió més personal del lladre i n'ofereix un retrat proper i multidimensional que evita l'estereotip, humanitza l'atracador i problematitza la seva situació. Tot i evitar el sentimentalisme -la cinta és plena de moments humorístics i defuig del que és naïf-, l’emoció està present a la proposta i aporta riquesa i complexitat al personatge i al seu cas particular.

Per últim, es convida a produir un cinema que canvii les formes i les maneres de mirar, que trenqui amb el que està preestablert, que

\footnotetext{
${ }^{9} \mathrm{El} \mathrm{meu} \mathrm{treball} \mathrm{de} \mathrm{camp} \mathrm{no} \mathrm{està} \mathrm{vinculat} \mathrm{només} \mathrm{als} \mathrm{tallers,} \mathrm{cinefòrums} \mathrm{i} \mathrm{projectes} \mathrm{de} \mathrm{cinema} \mathrm{participatiu} \mathrm{que} \mathrm{he} \mathrm{dinamitzat} \mathrm{durant} \mathrm{una} \mathrm{dècada}$ amb el Drac Màgic -amb col-lectius diversos, sobretot infants i joves-, sinó també a la meva activitat com a docent a la Universitat de Barcelona i a BAU, Centre Universitari de Disseny.
} 
abraci l'experimentació a tots els nivells i que busqui solucions formals pròpies i innovadores. El cinema situat és un cinema que estima la diversitat i celebra tota forma d'expressió, també la més poètica i apassionada. És un cinema híbrid, mestís i transdisciplinari. És actiu, mòbil, canviant i imprevisible. És obert, interpretatiu i contestable. És sensible al poder. És un cinema "de tensions, de ressonàncies, de transformacions, de resistències i de complicitats." (Haraway, 1995, p. 335).

La tesi doctoral que m’ocupa està basada en una pràctica. Em pregunto quan la creació fílmica pot ser font de coneixement vàlid i investigo també a través de la producció i realització d'un film ${ }^{10}$. La pel.lícula, en fase d'edició, explica el procés de creació d'un documental sobre una comunitat de religiosos de Barcelona i alhora en fa una anàlisi. La narrativa està centrada en el procés particular i encarnat d'intentar realitzar el documental sobre els frares -el text versa sobre la creació cinematogràfica-, però també repassa alguns aspectes concrets dels caputxins i altres de la meva vida personal i professional que contextualitzen la creació del film i ajuden a situar-me.

A través de la meva veu over, sobreposada a les imatges, s'estructura el discurs fílmic mentre estudio des de la pràctica les qüestions del mitjà cinematogràfic. Com puc filmar els caputxins? A quina distància i amb quina lent? Fins on puc posar la realitat en escena per afavorir la filmació? Quan filmo imatges observacionals, com puc oferir indicis de la meva presència com absència? Quan haig d'aparèixer dins l'enquadrament -a través de la imatge o el so- per presentar-me com a observador corpori i específic, sense intervenir més del que cal? La pel.lícula, com altres que recull Gonzalo de Lucas al seu article Ars Poetica. La veu del cineasta. (2013), "té un caràcter projectiu, són anotacions i cerques creatives d'un film per fer treballant, no des del paper o el guió, sinó des de l'experiència del cinema: la trobada amb els llocs i la revisió de les imatges.” El film no és només una inspecció i anàlisi de les imatges filmades, sinó també del procés d’ideació i muntatge de la pel.lícula dels caputxins, amb tot el que comporta en l'àmbit creatiu, expressiu, ètic i polític. A banda del metratge filmat al convent de Sarrià, el metratge autobiogràfic i alguns moments de making of, la pel.lícula inclou imat-

\footnotetext{
${ }^{10}$ El web https://lapelidelscaputxins.cargo.site/ aglutina la comunitat de pràctiques i altres objectes importants per a la meva recerca. El títol provisional del film és La pel.lícula dels caputxins.
} 
ges d'arxiu molt diverses i un conjunt de cites fílmiques: talls d’altres films que s'han preguntat el mateix, o alguna cosa similar, abans que jo. El film que proposo està basat en el muntatge de materials heterogenis, la qual cosa afavoreix i fa explícites la mescla, la interdisciplinarietat i la juxtaposició poètica, experimental i apassionada.

A continuació, comparteixo una prova de la seqüència inicial del film que pot funcionar també com a primer teaser de la proposta.

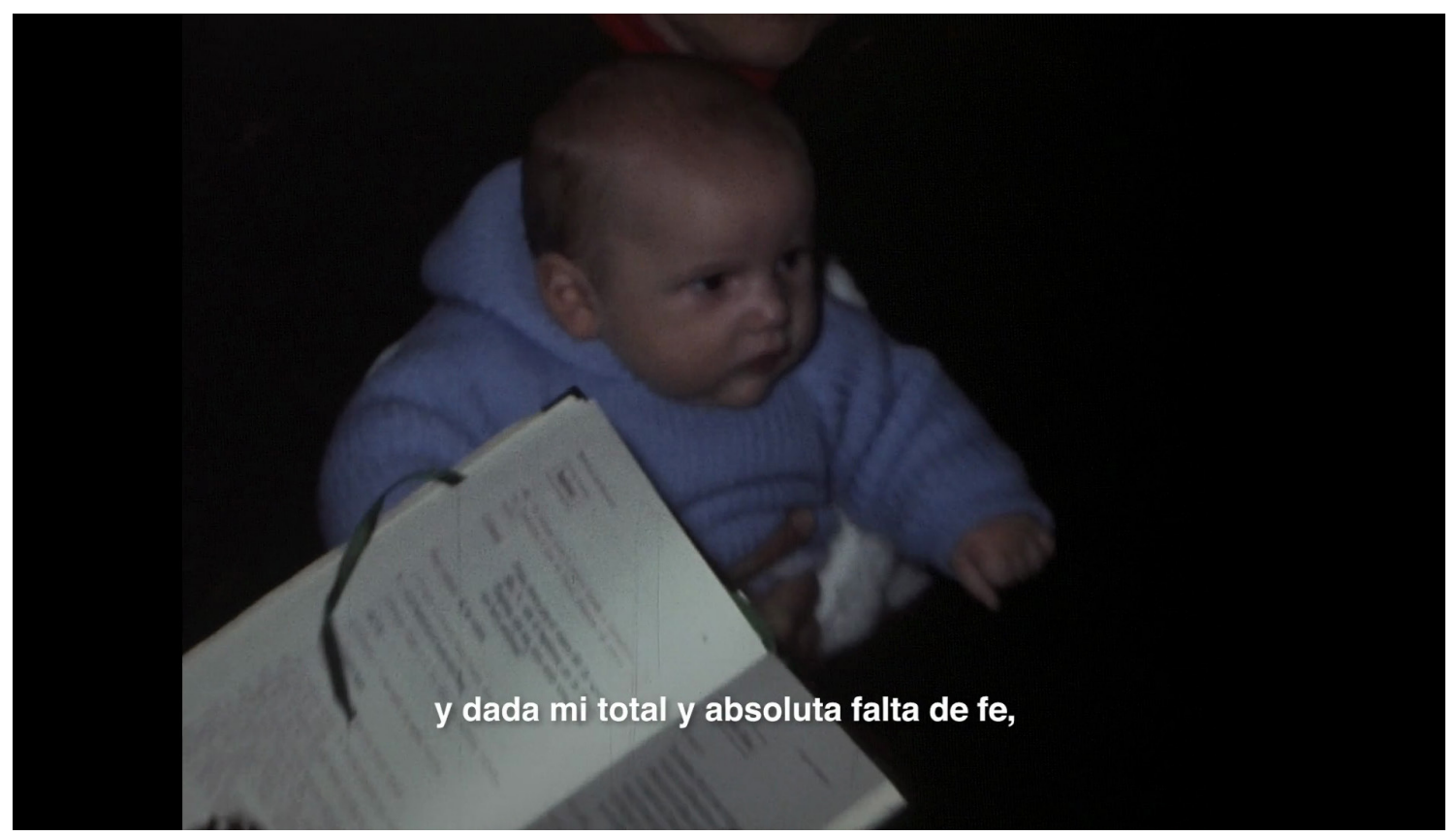

Teaser del film La pel-lícula dels caputxins (Pau Pericas, 2021).



Enllaçi codi QR al teaser https://vimeo.com/512080382 
Comparteixo també alguns fotogrames del teaser que considero rellevants i donen testimoni de la varietat de metratges, formats, relacions d'aspecte, textures i composicions de la peça:

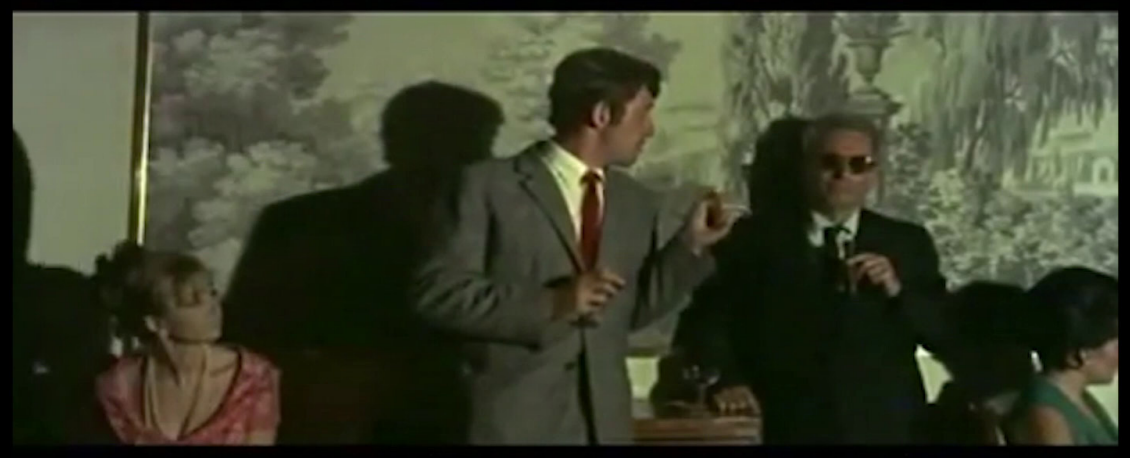

qué es el cine exactamente.

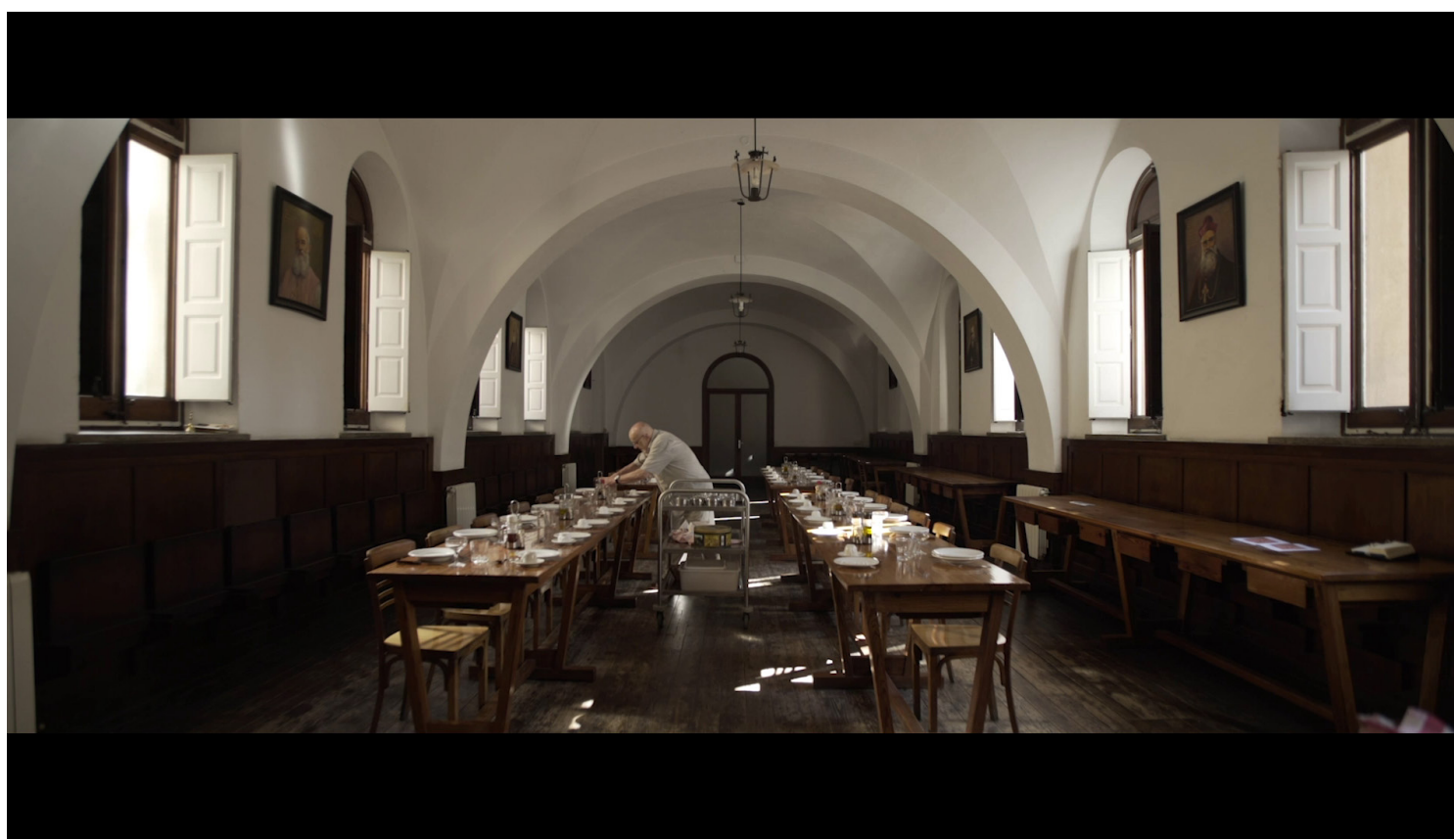





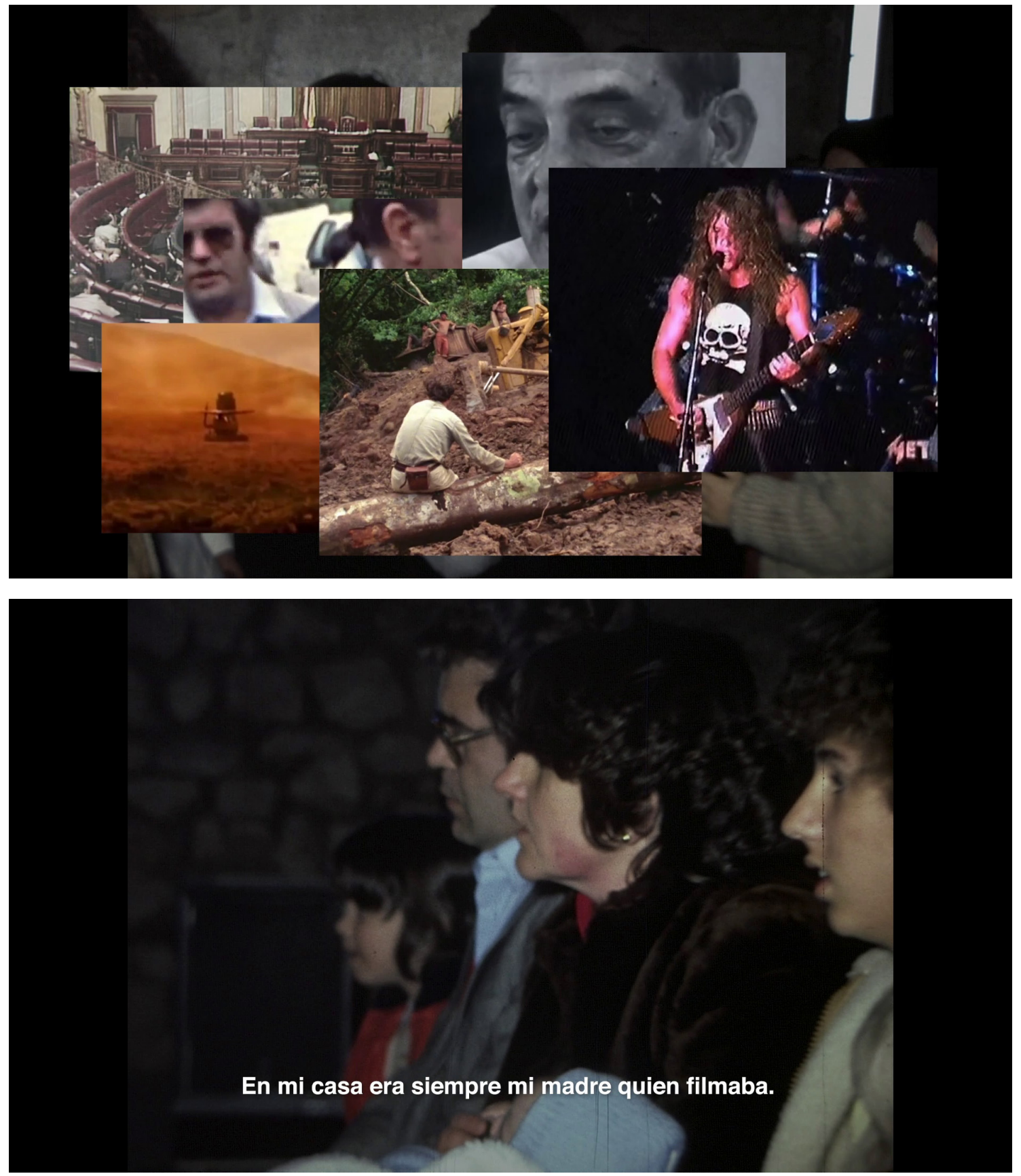

Sis fotogrames del teaser del film La pel.lícula dels caputxins (Pau Pericas, 2021).

El primer inclou una cita fílmica de la pel-lícula Pierrot Le Fou (Jean-Luc Godard, 1965). 
Amb les idees destil.lades de Haraway fins ara, conjuntament amb les obres de les cineastes anomenades, considero que és possible usar la idea de cinema situat com a forma d'anàlisi fílmica. Amb aquesta guia es pot reflexionar sobre el grau de situació que podem observar a cada proposta fílmica. No pretenc pas establir un cànon de cinema situat (això seria contrari a la pròpia natura -oberta, experimental, canviant i imprevisible- del cinema que busco), però sí voldria trobar unes línies d’anàlisi, un conjunt d'elements sobre els quals convé reflexionar, cas per cas, de forma particular. Al nucli dur del cinema situat, hi trobem films autoconscients i crítics que proposen una mirada ideològica -explícitament posicionada, però negociadora, oberta i solidària-del món històric que tracten. Aquests films presenten una preferència per adoptar el punt de vista dels col.lectius subjugats, estan disposats a denunciar les relacions de poder, sempre intenten innovar en la forma i cuiden les condicions de producció amb les quals es realitzen. Al cinema situat, resulta cabdal aquella idea que va expressar la ballarina, coreògrafa i cineasta Yvonne Rainer en resposta a Jean-Luc Godard: "No només s'ha de fer cinema polític: s'ha de fer políticament.” (Rainer, 1999).

Aquesta guia per analitzar el grau de situació de qualsevol proposta cinematogràfica m'ha de servir per portar a terme la meva pràctica fílmica -encara per fer-d'una manera situada. D'entrada, apareixen certes contradiccions que plantegen reptes interessants. Com puc defensar una mirada des de l'objectivitat feminista (decolonial i crítica amb el capitalisme) a través d'un film com La pel.lícula dels caputxins, escrit i dirigit per un home blanc, europeu i benestant, en el marc d'una tesi doctoral d'una universitat privada que representa una comunitat d'homes europeus de tradició marcadament colonialista? Les problemàtiques són clares. Quines contradiccions seré capaç de minimitzar? I a través de quins mecanismes? Escriure el guió i muntar el film amb certes nocions d'un cinema situat -i un intent d'un primer corpus fílmic- em pot servir per produir un film autocrític que proposi una negociació posicionada i una mirada inclusiva i solidària, no només respecte al gènere, sinó també la raça, l’ètnia, la classe i la religió.

Voldria realitzar un film que ofereixi una visió àmplia des del que és local i encarnat, que no pretengui representar la realitat sinó més aviat presentar realitats plausibles. Com podria legitimar l'apropiació d'imatges íntimes dels caputxins sense mostrar cap mena de vincle 
amb mi, sense una relació humana reconeguda i manifesta? Quin és el context que envolta i condiciona la producció i realització del film? De la complexa $\mathrm{i}$ inabastable realitat que suposa el fenomen dels caputxins de Sarrià, quins aspectes voldria tractar i des de quina perspectiva?

Donada aquesta voluntat contestatària de trencar amb les maneres de mirar preestablertes a la qual ens convida Haraway, La pel.lícula dels caputxins vol abraçar l'experimentació i la innovació, tant pel que fa la narració (acció, espai, temps, veu narradora i personatges) com la representació (en la posada en escena, posada en quadre i posada en sèrie $\left.{ }^{11}\right)$. També es té molt en compte el poder expressiu i creatiu del disseny de so.

En l'àmbit de la narració, es proposa un film vertebrat per la meva pròpia veu que narra en primera persona del singular i fa el film autoconscient, és crítica amb la construcció de la pel-lícula i proposa dubtes i reflexió, tot incloent l'audiència. Es proposa, a més, una narrativa dèbil i fragmentària, plena de digressions per poder saltar en l'espai i el temps i reflexionar sobre la meva manera d'entendre el món, investigar la influència de la forma de filmar de la meva mare en el meu estil i parlar de problemàtiques polítiques i socials que estan esdevenint al meu voltant mentre rodo La pel.lícula dels caputxins.

Pel que fa a la representació, em vull centrar en aquells aspectes sobre els quals tinc un control total: la posada en quadre i la posada en sèrie. M'interessen especialment aquelles formes de fer que trenquen amb un llenguatge continuista. Així doncs, voldria evitar la continuïtat entre plans de diferent valor i l'ús del pla-contraplà, i també experimentar amb el contrast entre els diferents metratges usats. El muntatge és l'element fonamental de la construcció del film. Vull defugir el muntatge lineal i continuista, que pretén ser invisible. Al contrari, busco un muntatge que es fa evident, que es fa present per fer notar el film i el seu realitzador. És un muntatge que facilita la hibridació, la digressió i la connexió apassionada, que guia l'audiència i la sotmet a un impacte sensual i/o psicològic. El resultat final vol ser una proposta visualment

\footnotetext{
${ }^{11}$ Aquests tres nivells proposats per desgranar la representació audiovisual provenen del text "Cómo analizar un film" (Analisi del film, en la seva versió original, publicada l’any 1990) dels teòrics italians Francesco Casetti i Federico Di Chio. Opino que la classificació és exhaustiva i resulta molt útil per a tota la part visual, tot i que menysté la part sonora.
} 
heterogènia -fragmentària, canviant i mestissa-,- que juga sovint al collage, amb composicions de diferents imatges en pantalla partida que trenquen la linealitat de l'espai i el temps. La repetició i la parada, els dos aspectes transcendentals del muntatge cinematogràfic que destaca Giorgio Agamben (1998), s'usen al film al servei de l'anàlisi i el pensament de les imatges.

Com en el cas del tractament visual, el tractament sonor de la pel.lícula vol cercar també a consciència la hibridació i la mescla. El disseny sonor del film intenta descentrar la importància de la mirada per atorgar valor creatiu i expressiu a la mescla de les veus, els efectes de so i la música. A banda de treballar amb el so directe en sincronia, la pel.lícula planteja a vegades un disseny de so experimental creat mitjançant capes sonores complexes, amb formes de repetició, scratch, silenci i desconcordança entre imatge i so.

\section{Referències}

Agamben, G., 1998. L'image et la mémoire. París: Éditions Hoëbeke.

Apuntes para una película de atracos, 2018. [film] Dirigit per León Siminiani. Espanya: Pandora Cinema.

Aumont, J., Bergala, A., Marie, M., Vernet, M., 1996. Estética del cine. Espacio filmico, montaje, narración, lenguaje. Barcelona: Ediciones Paidós Ibérica.

Casetti, F. i Di Chio, F., 1990. Cómo analizar un film. Barcelona: Ediciones Paidós Ibérica.

De Lucas, G., 2013. Ars poetica. La veu del cineasta. A: Cinema Comparat/ive Cinema, n. 3, p. 47-57.

Debord, G., 1967. La Société du Spectacle. París: Gallimard.

El año del descubrimiento, 2020. [film] Dirigit per Luis López Carrasco. Espanya i Suïssa: LaCima Producciones i Alina Film.

Garcés, M., 2017. Nova il.lustració radical. Barcelona: Editorial Anagrama.

Ghost Dance, 1983. [film] Dirigit per Ken McMullen. EEUU: Channel 4 Television i ZDF.

Haraway, D., 1995. Ciencia, cyborgs y mujeres: la reinvención de la naturaleza.

Madrid: Ediciones Cátedra. 
Herman Slobbe, 1966. [film] Dirigit per Johan Van Der Keuken. Holanda: VPRO.

Herrero, Y., 2018. Miradas ecofeministas para revertir la guerra contra la vida. [vídeo] CENDEAC, 23 de maig de 2018. Recuperat de <https://youtu.be/Zg2eEs5sIhI> el 21 d'abril de 2021.

Los espigadores y la espigadora, 2000. [film] Dirigit per Agnès Varda. França: Ciné Tamaris.

Margarita y el lobo, 1969. [film] Dirigit per Cecília Bartolomé. Espanya: Escuela Oficial de Cinematografía (EOC).

Nichols, B., 1997. La representación de la realidad. Cuestiones y conceptos sobre el documental. Barcelona: Ediciones Paidós Ibérica.

Nicht löschbares Feuer, 1969. [film] Dirigit per Harun Farocki. Alemanya: Deutsche Filmund Fernsehakademie Berlin.

Où gît votre sourire enfoui?, 2001. [film] Dirigit per Pedro Costa. França i Portugal: Contracosta Produções.

Pierrot Le Fou, 1965. [film] Dirigit per Jean-Luc Godard. França i Itàlia: Dino de Laurentiis Cinematografica.

Rainer, Y., 1999. A Woman Who...: Essays, Interviews, Scripts. EEUU: The Johns Hopkins University Press.

Reassemblage: From the Firelight to the Screen, 1982. [film] Dirigit per Trinh T. Minha-ha. EEUU: Jean-Paul Bourdier.

Selva, M., 2020. Marta Selva - Sesión Especial Barbara Hammer. [vídeo] Festival Punto de Vista, 3 de març de 2020. Recuperat de <https://youtu.be/xjvyX6B5ZJs > el 9 de juny de 2021.

Sousa Santos, B. de, 2017. Justicia entre saberes: epistemologías del sur contra el epistemicidio. Madrid: Editorial Morata.

Taibo, C., 2017. Colapso: capitalismo terminal, transición ecosocial, ecofascismo. Buenos Aires: Libros de Anarres. 
Soc en Pau Pericas Bosch, realitzador audiovisual i professor associat a la Universitat de Barcelona i a BAU, Centre Universitari de Disseny. Soc llicenciat en Comunicació Audiovisual per la Universitat de Barcelona, màster en Estudis de Cinema i Audiovisual Contemporanis per la Universitat Pompeu Fabra i doctorand en Estudis Culturals a la Unitat de Doctorat i Recerca de BAU (UVic-UCC). Investigo sobre la creació audiovisual entesa com a mitjà d'expressió i forma de coneixement, l’ètica de les imatges i la posició de la realitzadora. 